\title{
ANÁLISE ECONÔMICA DA PRODUÇÃO AVÍCOLA DE CORTE POR GÊNERO EM DIFERENTES ESTRUTURAS DE GOVERNANÇA
}

\author{
Economic Analysis of Broiler Production by Gender in Different Governance Structures
}

\begin{abstract}
RESUMO
A avicultura de corte brasileira sustenta-se sobre a estrutura de governança híbrida estabelecida entre empresas integradoras e unidades de produção rural. Contudo, algumas empresas ainda investem na manutenção e aquisição de instalações próprias para criação das aves. Objetivou-se avaliar o desempenho zootécnico de frangos de corte de acordo com o gênero alojado e analisar o resultado econômico da atividade sob diferentes mecanismos de governança. Estudos de caso foram utilizados como procedimentos de pesquisa para avaliação da atividade em núcleos de criação da empresa integradora e de produtores rurais integrados. Dados primários sobre custos, receitas e indicadores zootécnicos foram coletados em 24 unidades de produção de aves pertencentes a uma empresa integradora e cinco produtores rurais integrados, localizados no estado de Minas Gerais. Foram utilizadas informações provenientes de 144 lotes de frangos de corte COBB ${ }^{\circledR}$ produzidos entre agosto de 2015 e agosto de 2016. Indicadores zootécnicos de lotes exclusivos para machos foram melhores que os observados para criação mista de aves e para lotes de fêmeas, respectivamente. Entretanto, na comparação dos resultados com os valores esperados para a linhagem, o potencial genético das aves poderia ter sido melhor aproveitado pelas unidades de produção rural. Independente do gênero das aves, análises econômicas indicaram que somente a criação de frangos de corte no modelo de integração foi capaz de conferir lucro econômico à atividade. Constatou-se que, para qualquer estrutura de governança avaliada, a criação de aves não se sustenta financeiramente sem receitas secundárias provenientes da venda de cama dos aviários.
\end{abstract}

Edgard Onoda Luiz Caldas

Universidade Federal de Minas Gerais

caldas.eol@gmail.com

André Luís Ribeiro Lima

Universidade Federal de Lavras

andre.lima@ufla.br

Leonardo José Camargos Lara

Universidade Federal de Minas Gerais

leolara@vet.ufmg.br

Recebido em: 28/04/2020. Aprovado em: 14/08/2020.

Avaliado pelo sistema double blind review

Avaliador científico: Eduardo César Silva.

DOI: 10.48142/2220201641

\begin{abstract}
The Brazilian poultry production is based on the hybrid governance structure established between integrators and rural production units. However, some companies still invest in the maintenance and acquisition of their own broiler breeding facilities. The objective was to evaluate the zootechnical performance of broilers according their gender and analyze the economic results of the activity under different governance mechanisms. Case studies were used as research procedures to evaluate the activity in the creation centers of the integrating company and integrated rural producers. Primary data on costs, income and zootechnical indicators were collected in 24 poultry production units belonging to one integrating company and five integrated rural producers, located in Minas Gerais. Information from 144 broiler lots produced between August 2015 and August 2016 was used. Zootechnical results of exclusive male flocks were better than those observed for breeding non-sexed birds and for female flocks, respectively. However, when comparing the evaluated lots with the COBB ${ }^{\circledR}$ Broiler Performance, the genetic potential of the birds could have been better used by the rural production units. Regardless of the gender of the birds, economic analyzes indicated that only the creation of broilers in the integration model was able to confer economic profit to the activity. It was found that, for any governance structure adopted, poultry production cannot be sustained financially in the medium and long terms without secondary revenues from the sale of poultry litter.
\end{abstract}

Palavras-chaves: Avicultura de Corte; Custos de Produção; Nova Economia Institucional.

Keywords: Poultry; Costs Production; Governance Structure; New Institutional Economics. 


\section{INTRODUÇÃO}

A avicultura de corte brasileira ocupa posição de destaque nos cenários nacional e internacional. O Brasil ocupa a terceira colocação na produção de frangos de corte em escala internacional e é o maior exportador mundial de carne de frango. Em se tratando de segurança alimentar, há mais de uma década, a carne de frango é a principal fonte de proteína animal dos brasileiros. Além disso, a avicultura de corte brasileira demonstra sua importância socioeconômica ao empregar mais de 3,6 milhões de trabalhadores e por responder por aproximadamente $1,5 \%$ do produto interno bruto nacional (ABPA, 2020; USDA, 2020).

Segundo a União Brasileira de Avicultura (UBABEF, 2011), o expressivo desenvolvimento da avicultura de corte brasileira se sustenta pela combinação da qualidade higiênico-sanitária de seus produtos, dos padrões de sustentabilidade adotados e do sistema de governança híbrido adotado pelas empresas abatedoras com grandes empresas rurais e milhares de pequenas unidades de produção familiar.

Entretanto, a despeito do panorama promissor associado ao sistema de integração, constata-se que empresas integradoras ainda utilizam mecanismos de governança via hierarquia para produção de frangos de corte. Assim, ao invés de ampliarem suas produções de aves por meio de contratos de integração, algumas agroindústrias investem na aquisição e manutenção de instalações próprias para a criação de aves.

Dentro deste contexto, objetivou-se analisar o resultado econômico da atividade sob diferentes mecanismos de governança com enfoque sobre o desempenho zootécnico de frangos de corte segundo o gênero alojado nas unidades de criação.

Este estudo tem como finalidade acrescentar informações de natureza econômica à discussão sobre a produtividade dos gêneros de frangos de corte criados em núcleos de empresas integradoras e de produtores rurais integrados. Além disso, esta pesquisa visa fornecer subsídios para que as integradoras avícolas orientem a expansão de suas atividades baseadas em princípios racionais e científicos.

\section{REFERENCIAL TEÓRICO}

\subsection{Panorama sobre análises econômicas e zootécnicas na produção de frangos de corte}

Estudos sobre desempenho produtivo de frangos de corte, de acordo com a linhagem e o gênero, indicam que os resultados zootécnicos da criação exclusiva de machos são melhores que os obtidos em galpões de aves não sexadas e de fêmeas (GOTTARDI et al., 2019; API et al., 2017 e MARTINS et al., 2012). Além destas constatações, Da Costa et al. (2017) ainda observaram que a produção mista (sem separação das aves de acordo com o sexo) favoreceu machos e prejudicou fêmeas em comparação com criações exclusivas para cada um desses gêneros.

De maneira geral, produtores de frangos de corte e outros profissionais da área valorizam sobremaneira indicadores zootécnicos em seus processos de tomada de decisão - tal qual observado com relação ao fator de produção ${ }^{1}$ (índice de eficiência produtiva). Dentro deste contexto, desconsideram que a melhor avaliação para uma empresa é a econômica, pois não necessariamente os melhores resultados zootécnicos implicam em maiores taxas de lucro na atividade (SOUZA; MICHELAN FILHO, 2004).

Segundo Mendes (1989, p. 124),

O índice perfeito de avaliação do desempenho produtivo seria aquele que conseguisse ordenar os parâmetros de avaliação de maneira que o melhor lote, tecnicamente falando, apresentasse o melhor índice e fosse, também, o mais lucrativo.

A primeira dificuldade em orientar o processo de tomada de decisão com base em premissas econômicas se encontra no próprio grau de interesse dos produtores rurais em gerenciar custos e receitas relacionadas com suas atividades. Figueira (2009) indicou que na Zona da Mata Mineira mais da metade dos produtores rurais integrados não realizava nenhum tipo de controle financeiro de suas atividades. Contudo, segundo a percepção dos próprios produtores, a estruturação financeira por meio do mapeamento de custos e receitas seria um dos fatores desencadeadores de sucesso na produção avícola de corte.

As variáveis de custo quando associadas às receitas permitem ao administrador da empresa rural verificar se determinada atividade opera com lucro ou prejuízo. De acordo com Reis (2007, p. 30),

os custos servem para verificar se e como os recursos empregados em um processo de produção estão sendo remunerados, possibilitando também verificar como está a rentabilidade da atividade em questão, comparada a outras alternativas de emprego do tempo e capital.

${ }^{1} \mathrm{O}$ fator de produção (índice de eficiência produtiva) é um indicador que utiliza resultados zootécnicos para avaliar a produtividade em cada ciclo de produção. Corresponde a multiplicação do ganho de peso médio diário pela viabilidade dividida pela conversão alimentar, obtidos em cada lote produzido. O resultado final, usualmente, é multiplicado por dez para ajuste de casas decimais. 
Em pesquisa realizada na região oeste de Minas Gerais, Carvalho, Fiúza e Lopes (2007) demonstram que a apuração de custos cria condições de o produtor rural verificar se sua atividade o remunera melhor que outras atividades econômicas passíveis de aplicação de seu capital e se é possível ou conveniente continuar a produção ao longo do tempo. Além disso, complementam que a análise da composição de custos relativos pode atuar como determinante de competitividade, ao passo que permite aos gestores do negócio concentrar esforços técnicos e gerenciais no sentido de aumentar a produtividade e lucratividade da empresa.

De acordo com Caldas et al. (2015) o sucesso da produção de frangos de corte em sistema de integração depende do equilíbrio entre resultados zootécnicos, custos e receitas. Em pesquisa realizada nos estados de Minas Gerais e São Paulo, os autores constataram que a atividade avícola de corte integrada pode gerar lucro econômico, mas é altamente dependente da receita proveniente da venda de cama produzida nos aviários.

\subsection{Nova Economia Institucional aplicada à avicultura de corte}

Sob a perspectiva da Nova Economia Institucional, Coase (1937) considerou que as firmas se inserem em um ambiente organizacional que ultrapassa os limites da teoria neoclássica. Assim, além dos tradicionais custos de produção, considerou a existência de custos provenientes das transações econômicas, denominados custos de transação.

Ao elaborar a Economia dos Custos de Transação, Williamson (1985) pressupôs hipóteses comportamentais vinculadas às transações: racionalidade limitada e oportunismo. A primeira envolve a elaboração de contratos incompletos, não obstante o esforço das partes em criar salvaguardas em uma negociação. A segunda resulta da ação dos agentes envolvidos com a finalidade de se obter vantagens unilaterais, o que pode ocorrer ex-ante ou ex-post à transação. Além disso, associou atributos às transações: a) especificidade de ativos - vinculada ao valor superior que determinado bem tem no seu uso corrente em comparação ao seu uso alternativo, associando-se também o conceito de custos irrecuperáveis (sunk-costs); b) incerteza - que se refere ao risco de descumprimento dos contratos ou ações oportunistas dos agentes envolvidos, derivadas da racionalidade limitada; c) frequência relacionada com a repetição e a intensidade com que a transação ocorre ao longo do tempo, que pode elevar a reputação das partes envolvidas e diminuir a incerteza em negociações futuras.
De acordo com Williamson (1985), para minimizar custos de transação, é necessário adotar estruturas de governança (via mercado, via relação contratual ou via hierárquica) compatíveis com os atributos das transações envolvidos em uma negociação. No mecanismo via mercado produtos e serviços podem ser adquiridos de qualquer agente econômico disposto a fornecê-los. No extremo oposto, na via hierárquica, a própria firma produz os insumos e os serviços que necessita por meio da verticalização da produção. De maneira intermediária, na estrutura de governança híbrida (via relação contratual) as firmas estreitam relações com seus fornecedores sem, contudo, internalizarem os processos e as atividades dentro de seus limites jurídicos.

Dentro deste contexto, a partir de análises de contratos na avicultura de corte no estado do Mato Grosso, Franco et al. (2011) verificaram que: a) as negociações de grãos e linhagens de aves eram realizadas via mercado; b) a produção de ovos férteis, a incubação e as fábricas de ração eram governadas via hierarquia, c) os transportes se realizavam via relação contratual e d) na produção de aves coexistiam mecanismos de governança híbrido e verticalizado. Verificou-se que aproximadamente $50 \%$ da produção de aves de corte no estado do Mato Grosso era realizada por meio de contratos com produtores rurais, porém, os autores não apresentaram argumentos capazes de elucidar totalmente esta situação.

Pereira, Melo e Santos (2007), ao analisarem os arranjos institucionais restritos a apenas uma cadeia em Minas Gerais, verificaram que a competitividade alcançada pela empresa analisada estava de acordo com os mecanismos de governança adotados. No caso do abate das aves e transporte de produtos prontos e da incubação de ovos a empresa adotava a estruturas de governança hierárquicas, que condiziam com a necessidade de controle total desses processos. No que se refere a criação de frangos, para que mercados internacionais fossem atendidos com produtos de qualidade sanitária garantida e baixo custo, utilizava-se o sistema híbrido com produtores rurais. Neste caso, a justificativa encontrada para a adoção da relação contratual se embasou na possibilidade de contratação de mão de obra de qualidade com baixo custo.

Pinotti e Paulillo (2007), ao compararem agroindústrias avícolas de Santa Catarina e com as da macrorregião de Ribeirão Preto, identificaram a existência de fatores não alinhados com a Economia dos Custos de Transação que influenciaram o surgimento de estruturas de governança distintas na organização dos agentes nas cadeias de frangos de corte. Fatores relacionados aos 
aspectos históricos, culturais, políticos, financeiros e de mercados conduziram a atividade avícola catarinense a um elevado nível de coordenação da cadeia por meio de contratos de integração entre a agroindústria e produtores rurais. Na macrorregião paulista relatou-se a coexistência de estruturas hierarquizadas, estruturas de governanças híbridas e de agentes que operam via mercado de forma restrita (produtores independentes de aves e abatedouros que não possuem próprio rebanho de aves).

Em consonância com os argumentos apresentados por aqueles autores, Rodrigues et al. (2011) constataram que no estado de Tocantins, devido aos mesmos aspectos citados, as estruturas de governança adotadas na cadeia avícola de corte possuíam características próprias marcadas por atributos particulares do espaço em que se encontravam.

No que se refere a viabilidade econômica da produção de frangos de corte, segundo a estrutura de governança adotada por empresas integradoras, Caldas, Lara e Lima (2019) verificaram que a produção de frangos em sistema de integração é melhor alternativa econômica que adotar a governança via hierarquia. De acordo com os resultados de pesquisa realizada em Minas Gerais, os autores constataram que o custo como mão de obra eleva sobremaneira o custo total da produção verticalizada de frangos de corte.

\section{METODOLOGIA}

Este estudo possui natureza aplicada e foi realizado por meio de abordagem quantitativa da realidade. Adotou-se a estratégia de pesquisa baseada em estudos de casos múltiplos incorporados (YIN, 2005) para avaliar resultados econômicos e zootécnicos da criação de frangos de corte, de acordo com o gênero das aves alojadas nos núcleos de produção.

A pré-seleção das fontes de dados foi realizada para atender atributos de qualidade dos estudos de caso (YIN, 2005). Sob sigilo de nomes e referências que os pudessem identificar, três empresas integradoras e 15 produtores rurais integrados pertencentes a mesma macrorregião mineira compuseram as fontes de dados iniciais para a pesquisa.

Os indicadores zootécnicos, procedimentos técnicos, custos e receitas foram solicitados diretamente às empresas integradoras e aos produtores rurais integrados. Conforme definição de Megliorini (2012), como custos fixos e variáveis foram incorporados ao valor final do produto, utilizou-se o método de custeio por absorção para o cálculo do custo total de produção. Os custos foram calculados de acordo com metodologia proposta pela EMBRAPA - CNPSA (GIROTTO; SOUZA, 2006;
MIELE et al., 2010). O modelo utilizado para estruturação dos custos baseou-se em publicações de Matsunaga et al. (1976) e Reis (2007) e eles foram agrupados da seguinte maneira: a) quinze categorias de custo operacional efetivo ${ }^{2}$ (mão de obra, calefação, substrato para cama, energia elétrica, manutenção, serviço de apanha, assistência técnica, produtos veterinários, limpeza e desinfecção, eventuais, aluguel, Funrural, seguro, licenciamento ambiental, outros custos); b) duas categorias de custo operacional fixo (mão de obra familiar e depreciação) e c) duas categorias de custo alternativo (custo alternativo sobre o custo operacional efetivo total e custo alternativo sobre ativo imobilizado). Além disso, foram calculados o custo operacional total, o custo total de produção e os custos médios associados a cada uma dessas categorias, em reais por quilogramas de peso vivo produzido em cada lote.

Avaliações de adequação e verossimilhança das informações foram realizadas à medida que os dados foram coletados e apenas uma empresa integradora, com três núcleos próprios de produção, e cinco produtores rurais integrados foram selecionados para a etapa final de análises econômicas e de indicadores zootécnicos.

As principais características dos núcleos de produção da empresa integradora (Núcleo IT) e dos núcleos de produtores rurais integrados (Núcleo PR) se encontram na Tabela 1.

De acordo com o gênero alojado em cada núcleo, as unidades de produção foram agrupadas conforme descrito na Tabela 2.

As análises dos dados foram realizadas em conjunto, por gênero alojado em cada núcleo de criação, por meio da técnica específica de adequação ao padrão (YIN, 2005). Adotou-se metodologia simplificada de análise econômica conforme indicado por Hoffmann et al. (1992), Lampert (2003), Reis (2007) e CONAB (2010). Utilizou-se indicadores de eficiência econômica sob a perspectiva do empreendedor, segundo proposição teórica de Guiducci et al. (2012).

As análises se realizaram em dois cenários econômicos: no primeiro foi considerada a receita total obtida na atividade (receitas com venda de aves e venda de cama de aviário) e, no segundo, desconsideraram-se as receitas secundárias (receita com venda de cama dos aviários) vinculadas ao processo de produção.

\footnotetext{
${ }^{2}$ Nos contratos de integração avícola a empresa integradora é responsável por fornecer pintos de um dia, rações, transportes e assistência técnica aos produtores integrados. Assim, conforme metodologia proposta pela EMBRAPA - CNPSA (GIROTTO E SOUZA, 2006; MIELE et al., 2010) os custos destes insumos e serviços não foram contabilizados no cálculo do custo total das unidades de produção rural.
} 
TABELA 1 - Número de trabalhadores e de unidades de produção por núcleo de criação

\begin{tabular}{|c|c|}
\hline \multicolumn{2}{|c|}{ Núcleo IT 01} \\
\hline Número de trabalhadores & 26 trabalhadores contratados permanentes \\
\hline Número de galpões & Oito galpões próprios \\
\hline Sistemas de climatização & Pressão negativa com SRAE* \\
\hline Fornecimento de ração / água & Automatizado (Tuboflex) / Nipple \\
\hline \multicolumn{2}{|c|}{ Núcleo IT 02} \\
\hline Número de trabalhadores & 31 trabalhadores contratados permanentes \\
\hline Número de galpões & 11 galpões arrendados \\
\hline Sistemas de climatização & Pressão positiva com SRAE* \\
\hline Fornecimento de ração / água & Automatizado (Tuboflex) / Pendular \\
\hline \multicolumn{2}{|c|}{ Núcleo IT 03} \\
\hline Número de trabalhadores & 27 trabalhadores contratados permanentes \\
\hline Número de galpões & Nove galpões próprios \\
\hline Sistemas de climatização & Pressão positiva com SRAE* \\
\hline Fornecimento de ração / água & Automatizado (Tuboflex) / Nipple ou Pendular \\
\hline \multicolumn{2}{|c|}{ Núcleo PR 01} \\
\hline Número de trabalhadores & O proprietário mais um membro da família \\
\hline Número de galpões & Dois galpões próprios \\
\hline Sistemas de climatização & Pressão positiva com SRAE* \\
\hline Fornecimento de ração / água & Automatizado (Tuboflex) / Pendular \\
\hline \multicolumn{2}{|c|}{ Núcleo PR 02} \\
\hline Número de trabalhadores & O proprietário mais um trabalhador contratado permanente \\
\hline Número de galpões & Três galpões próprios \\
\hline Sistemas de climatização & Pressão positiva com SRAE* \\
\hline Fornecimento de ração / água & Automatizado (Tuboflex) / Nipple \\
\hline \multicolumn{2}{|c|}{ Núcleo PR 03} \\
\hline Número de trabalhadores & O proprietário mais um membro da família por meio período \\
\hline Número de galpões & Um galpão próprio \\
\hline Sistema de climatização & Pressão positiva com SRAE* \\
\hline Fornecimento de ração / água & Automatizado (Tuboflex) / Nipple \\
\hline \multicolumn{2}{|c|}{ Núcleo PR 04} \\
\hline Número de trabalhadores & Somente o arrendatário** \\
\hline Número de galpões & Um galpão arrendado \\
\hline Sistema de climatização & Pressão positiva com SRAE* \\
\hline Fornecimento de ração / água & Automatizado (Tuboflex) / Pendular \\
\hline \multicolumn{2}{|c|}{ Núcleo PR 05} \\
\hline Número de trabalhadores & Somente o proprietário \\
\hline Número de galpões & Um galpão próprio \\
\hline Sistema de climatização & Pressão positiva com SRAE* \\
\hline Fornecimento de ração / água & Automatizado (Tuboflex) / Pendular \\
\hline
\end{tabular}

Fonte: Elaborado pelos autores, segundo resultados da pesquisa

*SRAE - Sistema de resfriamento adiabático evaporativo

**Em 28,5\% dos lotes avaliados utilizou-se mão de obra contratada permanente 
TABELA 2 - Descrição das fontes de dados utilizadas para análise de resultados econômicos e zootécnicos por gênero de criação, de acordo com núcleos da empresa integradora (Núcleo IT) núcleos de produtores rurais integrados (Núcleo PR) e galpões (GP) de criação de aves

\begin{tabular}{cccc}
\hline & Fêmeas & Machos & Misto \\
\hline Núcleo IT 01 & 18 lotes (GP 03, 04, 05) & 06 lotes (GP 07) & - \\
Núcleo IT 02 & 18 lotes (GP 02, 04, 09) & 12 lotes (GP 01, 08) & 6 lotes (GP 04) \\
Núcleo IT 03 & 18 lotes (GP 02, 05, 08) & 18 lotes (GP 01, 03, 07) & - \\
Núcleo PR 01 & 6 lotes (GP 01) & 6 lotes (GP 02) & 6 lotes (GP 03) \\
Núcleo PR 02 & 6 lotes (GP 01) & 6 lotes (GP 02) & 6 lotes \\
Núcleo PR 03 & - & - & 6 lotes \\
Núcleo PR 04 & - & - & 6 lotes \\
Núcleo PR 05 & - & - & \\
\hline
\end{tabular}

Fonte: Elaborado pelos autores, segundo resultados da pesquisa

O período considerado para o cálculo dos custos médios de produção abrangeu os dados coletados entre agosto de 2015 a agosto de 2016. Foram utilizadas informações de 144 lotes de frangos de corte da linhagem $\mathrm{COBB}^{\circledR}$ produzidos em 24 instalações de criação. A duração média de cada lote produzido, incluindo-se período de vazio sanitário posterior a cada ciclo de produção, foi de 60 dias, perfazendo um total de seis lotes criados por ano em cada galpão.

\section{RESULTADOS E DISCUSSÃO}

De acordo com cada gênero, são apresentados na Tabela 3 o número médio de aves alojadas, a densidade média ao alojamento e a produtividade média, por lote criado em unidade de produção.

Os fatores de produção ou índices de eficiência produtiva (FP = ganho de peso médio diário das aves * viabilidade do lote * 10 / conversão alimentar) por gênero criado em cada núcleo de produção, bem como suas médias calculadas para cada gênero, são apresentados na Figura 1.

De acordo com os resultados tabelados para a linhagem COBB ${ }^{\circledR}$ (COBB-VANTRESS, 2015), constata-se que os resultados médios obtidos nos núcleos analisados (Figura 1) estiveram abaixo do previsto para a linhagem de aves. Segundo a tabela da linhagem - aves com mesma idade média considerada para cada gênero pesquisado - 0 fator de produção para machos deveria ter sido de 411,80, para fêmeas 359,89 e para aves não sexadas (misto) 388,77. Isso indica que os potenciais genéticos das aves poderiam ter sido melhor explorados pela empresa integradora e pelos produtores rurais integrados, pois os resultados médios para machos, para fêmeas e para aves não sexadas (misto) foram, respectivamente, 78,7\%, 76,3\% e 78,1\% dos previstos na tabela de linhagem (COBB-VANTRESS, 2015).

TABELA 3 - Número de médio de aves alojadas, densidade média ao alojamento e produtividade média, em núcleos da empresa integradora (IT) e em núcleos de produtores rurais integrados (PR) de acordo com o gênero criado em cada unidade de produção.

\begin{tabular}{ccccc}
\hline Gênero & Núcleo & $\begin{array}{c}\text { Aves } \\
\text { alojadas } \\
\text { (cabeças) }\end{array}$ & $\begin{array}{c}\text { Densidade } \\
\text { (aves/m²) }\end{array}$ & $\begin{array}{c}\text { Produção } \\
\text { de carne } \\
\left(\mathrm{kg} / \mathrm{m}^{2}\right)\end{array}$ \\
\hline Macho & IT 01 & 36.472 & 15,32 & 37,84 \\
Macho & IT 02 & 29.467 & 13,13 & 31,34 \\
Macho & IT 03 & 29.329 & 13,77 & 31,86 \\
Macho & PR 01 & 23.614 & 13,42 & 32,54 \\
Macho & PR 02 & 20.500 & 12,84 & 32,76 \\
Fêmea & IT 01 & 35.252 & 17,15 & 38,42 \\
Fêmea & IT 02 & 27.061 & 14,46 & 30,81 \\
Fêmea & IT 03 & 29.891 & 15,30 & 32,95 \\
Fêmea & PR 01 & 24.040 & 15,61 & 33,28 \\
Fêmea & PR 02 & 20.150 & 15,01 & 33,37 \\
Misto & IT 03 & 44.244 & 14,36 & 33,82 \\
Misto & PR 02 & 24.990 & 14,13 & 33,56 \\
Misto & PR 03 & 28.867 & 13,75 & 33,52 \\
Misto & PR 04 & 24.421 & 14,45 & 32,81 \\
Misto & PR 05 & 8.000 & 13,68 & 31,68 \\
\hline
\end{tabular}

Fonte: Elaborado pelos autores, segundo resultados da pesquisa

Organizações Rurais \& Agroindustriais, Lavras, 22:e1641, 2020 


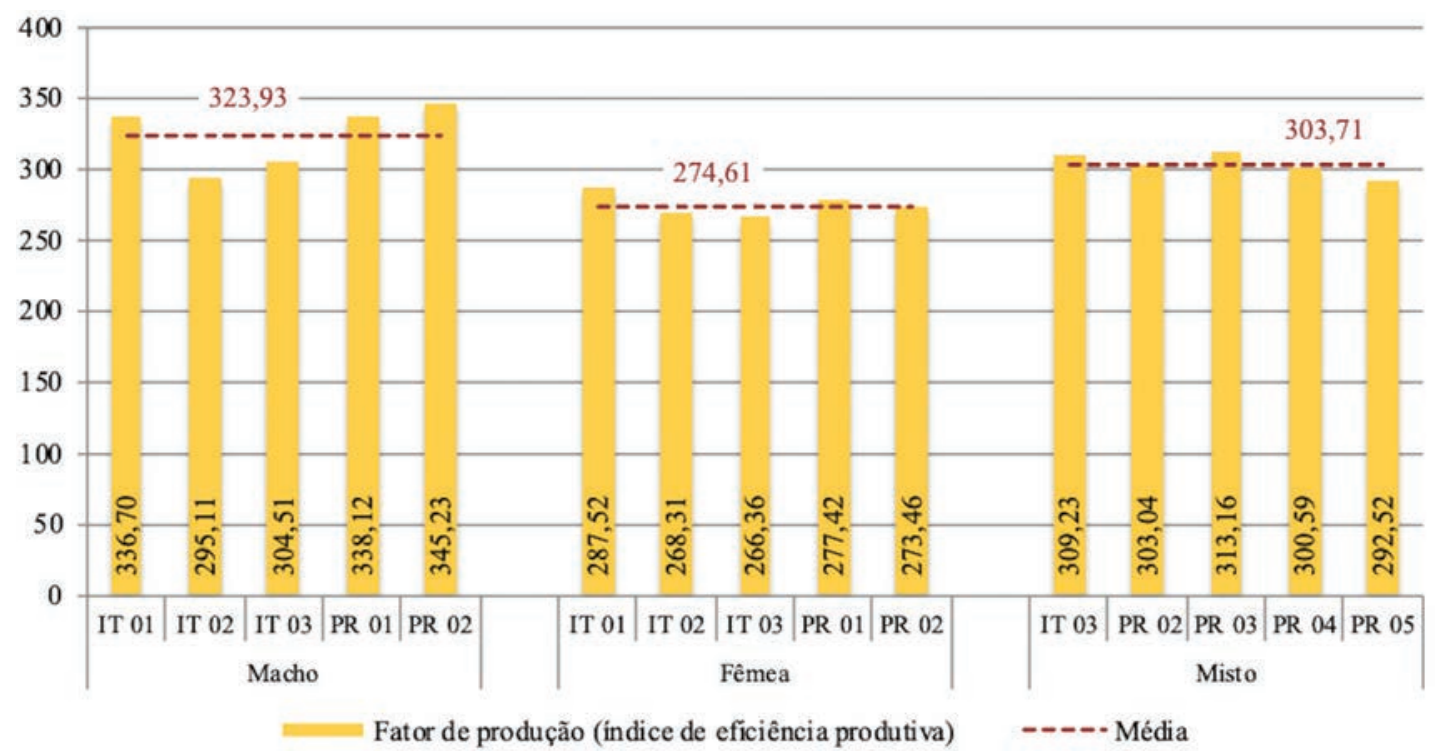

FIGURA 1 - Fator de produção (índice de eficiência produtiva) por gênero das aves e média por gênero em cada ciclo de produção para núcleos da empresa integradora (IT) e para núcleos de produtores rurais integrados (PR)

Fonte: Elaborado pelos autores, segundo resultados da pesquisa

A diferença entre os resultados zootécnicos observados nesta pesquisa em comparação com os tabelados para a linhagem (COBB-VANTRESS, 2015) indica que o processo de criação de aves nos núcleos avaliados poderia ter sido melhor executado. Os valores expressos na tabela de linhagem $\mathrm{COBB}^{\circledR}$ refletem o aproveitamento máximo das características genéticas das aves. Assim sendo, quanto melhor a qualidade de fatores relacionados com a nutrição, a sanidade, o manejo geral e a ambiência nas instalações de criação, tanto maior será a expressão do potencial genético dos animais.

Gottardi et al. (2019), em estudo sobre o efeito do gênero de frangos de corte sobre seus desempenhos produtivos, também se depararam com menor rendimento zootécnico dos lotes avaliados na pesquisa em comparação com os apresentados na tabela de linhagem (COBBVANTRESS, 2015). Segundo os autores, o estresse térmico sofrido pelas aves seria uma possível explicação para este pior desempenho, uma vez que o sistema de climatização utilizados nos galpões de criação foi insuficiente para garantir o conforto térmico necessário aos animais.

Por meio das médias apresentadas na Figura 1, verifica-se que o fator de produção obtido em aviários em que foram alojados somente machos $(\mathrm{FP}=323,93)$ foi $18 \%$ superior ao apresentado em instalações exclusivas de fêmeas ( $F P=274,61)$ e 6,7\% maior que em galpões com aves não sexadas ( $\mathrm{FP}=303,71)$.

Gottardi et al. (2019), Api et al. (2017), Da Costa et al. (2017) e Martins et al. (2012), em avaliações de produtividade associadas à separação das aves de acordo com seus gêneros, também constataram que lotes exclusivos de machos apresentaram melhores indicadores zootécnicos que lotes de aves não sexadas (mistas) e lotes de fêmeas.

Segundo Stringhini et al. (2003), frangos de corte machos apresentam maior ganho de peso e melhor conversão alimentar que fêmeas. Api et al. (2017), justificam estes resultados devido ao acumulo precoce de gordura nas fêmeas em razão da puberdade sexual ocorrer mais cedo que em machos.

Deve-se ressaltar, entretanto, que os resultados individuais obtidos em galpões de machos não serão, via de regra, maiores que os alcançados em lotes mistos de aves. Ao serem confrontados os resultados obtidos por gênero alojado nos núcleos, observa-se que os núcleos IT 03 Misto e PR 03 Misto apresentaram melhores índices de eficiência produtiva que os apresentados pelos núcleos IT 02 Macho e IT 03 Macho. Além disso, o núcleo PR 02 Misto também alcançou melhor fator de produção que o núcleo IT 02 Macho. 
Apesar de novas pesquisas serem necessárias para determinar a razão pela qual lotes de aves não sexadas tenham apresentado fator de produção superior ao observado para lotes de machos, sugere-se que pequenas variações no manejo geral das aves e na ambiência podem ser uma possível explicação para o resultado superior em favor dos lotes de aves mistas (machos e fêmeas criados no mesmo galpão).

Tendo em vista que a genética, a nutrição, os protocolos sanitários e o manejo geral eram padronizados e semelhantes para todos os núcleos, na comparação entre os núcleos de machos, constata-se que tecnologias de climatização mais modernas não implicaram necessariamente em melhores resultados zootécnicos. Embora o fator de produção do núcleo de machos IT 01 $(\mathrm{FP}=336,70)$ tenha sido alcançado em galpão climatizado por pressão negativa com paredes de alvenaria, os núcleos de machos PR 01 e PR 02, obtiveram melhores indicadores de produção (respectivamente, $\mathrm{FP}=338,12$ e FP = 345,23) em galpões climatizados por pressão positiva.

Segundo a Tabela 3, este pior desempenho do núcleo de machos IT 01 confirma resultados de pesquisa de Mendes e Komiyama (2011), que observaram que o aumento de densidade nos aviários pode prejudicar o desempenho das aves e, como consequência, diminuir o fator de produção.

Por outro lado, se a análise for realizada de acordo com a produtividade obtida em cada núcleo (Tabela 3), verifica-se que este é um ponto controverso a respeito do índice de eficiência produtiva em granjas avícolas de corte ${ }^{3}$.

Sob esta perspectiva, a despeito de o fator de produção do núcleo de machos IT 01 ter sido menor que o apresentado pelos núcleos de machos PR 01 e PR 02 (Tabela 3), verifica-se que a produtividade (em quilos de carne por metro quadrado) do núcleo de machos IT 01 foi maior que o apresentado pelos núcleos de machos PR 01 e PR 02. Tal fato decorre do maior adensamento de aves no núcleo IT 01, sob condições de climatização adequadas.

No que se refere à comparação entre núcleos de fêmeas, verifica-se que o núcleo de fêmeas IT $01(\mathrm{FP}=$ 287,52) apresentou resultado 12,91 pontos acima da média calculada para fêmeas ( $F P=274,61)$. Considerando que a genética, a nutrição, os protocolos sanitários e o manejo geral eram similares para todos os núcleos em análise,

${ }^{3} \mathrm{O}$ fator de produção (índice de eficiência produtiva - IEP) é calculado utilizando-se como variáveis a viabilidade, o ganho de peso médio diário e a conversão alimentar dos lotes criados, sem considerar o adensamento de aves nos galpões ou a produtividade em quilos de carne por metro quadrado. sugere-se que esse resultado superior esteja relacionado com a tecnologia de climatização por pressão negativa utilizada somente nos galpões de fêmeas deste núcleo.

Na Tabela 4 encontram-se os custos médios de produção, por gênero das aves alojadas, de acordo com a classificação proposta por Matsunaga et al. (1976) e Reis (2007).

Para cada categoria de gênero (machos, fêmeas e misto), verifica-se na Tabela 4 que os custos operacionais e totais médios (em reais por quilograma de carne produzido) associados aos núcleos da empresa integradora foram maiores que os apresentados pelos núcleos de produtores rurais integrados (exceto para o núcleo PR 05 misto, devido a sua impossibilidade de diluir custos fixos pela baixa capacidade de alojamento de aves, conforme apresentado na Tabela 3). Esta constatação está de acordo com Caldas, Lara e Lima (2019), que verificaram que os custos de produção de frangos de corte, independente do gênero das aves alojadas, em núcleos sob estrutura de governança hierárquica foram maiores que os observados para núcleos sob governança híbrida, devido principalmente ao custo com mão de obra para o desenvolvimento das mesmas atividades.

Na Figura 2 foram expostas as receitas primárias médias por gênero em cada núcleo de criação, bem como as médias de acordo com cada gênero alojado. As receitas secundárias foram desconsideradas para que fosse possível relacionar indicadores zootécnicos com as remunerações pagas pelas aves produzidas.

Apesar de a média do fator de produção (índice de eficiência produtiva) de aviários exclusivos para machos $(\mathrm{FP}=323,93)$ ter sido $18 \%$ superior ao resultado de fêmeas ( $\mathrm{FP}=274,61)$ e $6,7 \%$ maior que o de aves não sexadas (FP = 303,71), como apresentado na Figura 1, essa diferença se tornou ainda mais acentuada em termos de remuneração pela produção das aves (Figura 2). Em média, a receita primária obtida em unidades de criação exclusivas para machos (R\$ 0,2170/ kg) foi 34,6\% maior que o recebido em galpões para fêmeas ( $\mathrm{R} \$ 0,1612 / \mathrm{kg}$ ) e 12,6\% superior ao de aves não sexadas ( $\mathrm{R} \$ 0,1927 / \mathrm{kg}$ ).

Conforme discussão realizada com dados apresentados na Figura 1, de maneira geral, frangos de corte macho apresentam melhores indicadores zootécnicos que fêmeas. Contudo, a despeito desta informação, o cálculo de remuneração utilizado pela empresa integradora era realizado independentemente do gênero criado nas unidades de produção, isto é, quanto maior o fator de produção obtido pelo lote maior seria o valor pago por ave entregue para o abate. 
TABELA 4 - Custo operacional efetivo médio (COEMe), custo médio com mão de obra familiar (MOFMe), custo médio com depreciação (DeprMe), custo médio alternativo (CAltMe), custo operacional total médio (COTMe) e custo total médio de produção (CTMe), em reais por quilogramas de peso vivo produzido em cada lote, por gêneros alojados, para núcleos da empresa integradora (IT) e para núcleos de produtores rurais integrados (PR)

\begin{tabular}{lccccccc}
\hline Gênero & Núcleo & COEMe & MOFMe & DeprMe & CAltMe & COTMe & CTMe \\
\hline Macho & IT 01 & 0,3175 & 0,0000 & 0,0647 & 0,0501 & 0,3822 & 0,4324 \\
Macho & IT 02 & 0,4262 & 0,0000 & 0,0000 & 0,0046 & 0,4262 & 0,4308 \\
Macho & IT 03 & 0,3566 & 0,0000 & 0,0462 & 0,0285 & 0,4028 & 0,4313 \\
Macho & PR 01 & 0,1621 & 0,0462 & 0,0483 & 0,0422 & 0,2566 & 0,2988 \\
Macho & PR 02 & 0,1882 & 0,0316 & 0,0466 & 0,0535 & 0,2664 & 0,3200 \\
Fêmea & IT 01 & 0,3218 & 0,0000 & 0,0566 & 0,0379 & 0,3785 & 0,4163 \\
Fêmea & IT 02 & 0,4566 & 0,0000 & 0,0000 & 0,0049 & 0,4566 & 0,4615 \\
Fêmea & IT 03 & 0,3543 & 0,0000 & 0,0448 & 0,0280 & 0,3991 & 0,4270 \\
Fêmea & PR 01 & 0,1643 & 0,0526 & 0,0520 & 0,0365 & 0,2689 & 0,3055 \\
Fêmea & PR 02 & 0,2132 & 0,0222 & 0,0502 & 0,0500 & 0,2855 & 0,3355 \\
Misto & IT 03 & 0,3713 & 0,0000 & 0,0436 & 0,0263 & 0,4149 & 0,4412 \\
Misto & PR 02 & 0,1963 & 0,0339 & 0,0474 & 0,0522 & 0,2776 & 0,3298 \\
Misto & PR 03 & 0,1352 & 0,0575 & 0,0453 & 0,0442 & 0,2380 & 0,2822 \\
Misto & PR 04 & 0,2222 & 0,0482 & 0,0000 & 0,0029 & 0,2704 & 0,2733 \\
Misto & PR 05 & 0,1832 & 0,1440 & 0,0529 & 0,0580 & 0,3801 & 0,4381 \\
\hline
\end{tabular}

Fonte: Elaborado pelos autores, segundo resultados da pesquisa

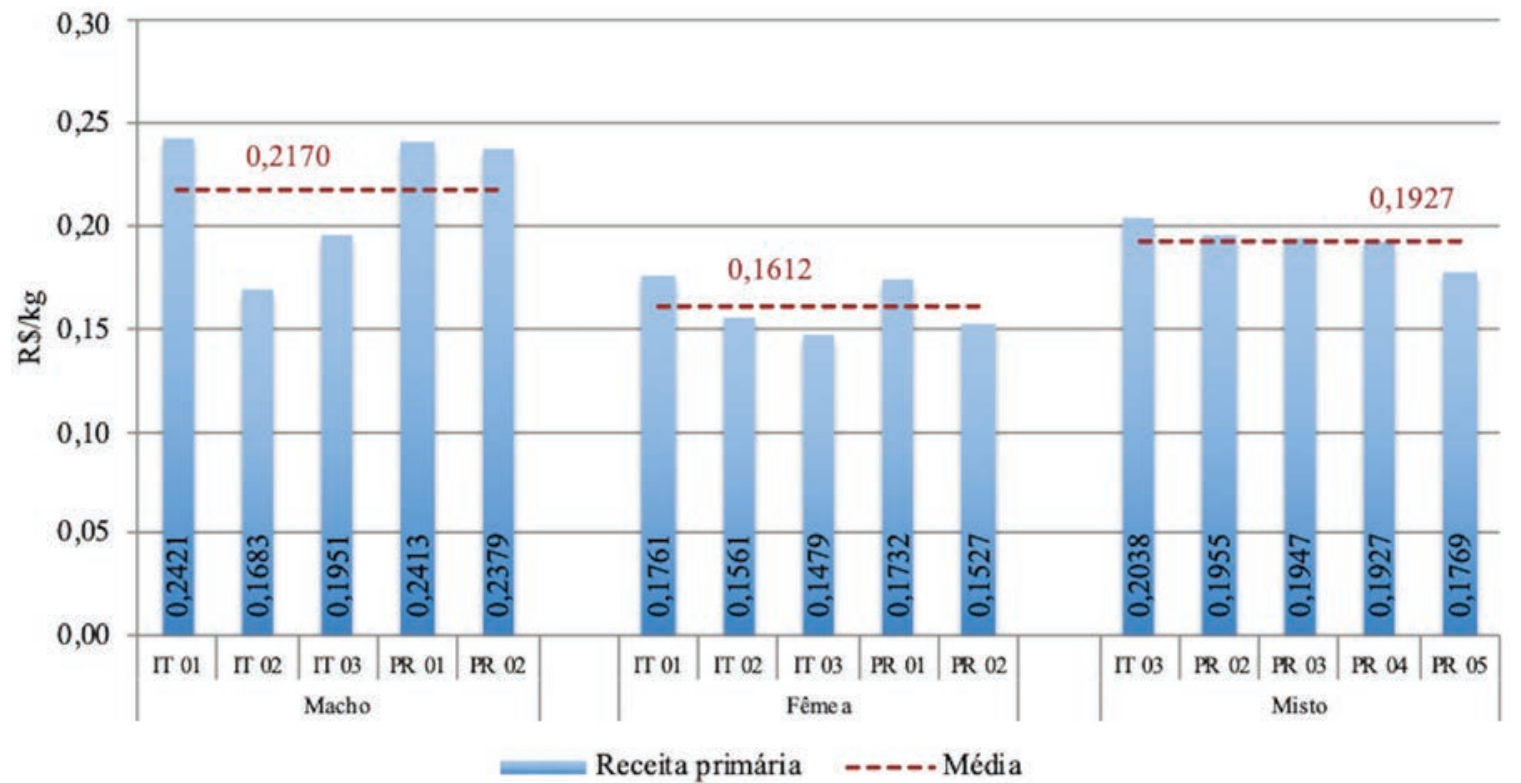

FIGURA 2 - Receita primária média por gênero e média da receita por gênero, em reais por quilograma de peso vivo produzido, obtida em cada ciclo de produção, para núcleos da empresa integradora (IT) e para núcleos de produtores rurais integrados (PR)

Fonte: Elaborado pelos autores, segundo resultados da pesquisa 
Dentro desse contexto, unidades de criação de fêmeas acabavam sendo desfavorecidas, haja vista que, naturalmente, esse gênero de aves atinge menor desempenho que o alcançado por machos. De acordo com os resultados zootécnicos apresentados na Figura 1 e os resultados esperados para aves da linhagem $\mathrm{COBB}^{\circledR}$, o fator de produção em galpões de fêmeas $(\mathrm{FP}=274,61)$ foi $23,7 \%$ abaixo do esperado para linhagem (FP = $301,34)$ e o de machos $(\mathrm{FP}=323,93)$ foi $21,3 \%$ menor que o previsto para aves $\mathrm{COBB}^{\circledR}$. Entretanto, observa-se na Figura 2 que a remuneração de fêmeas (R \$ 0,1612/ $\mathrm{kg}$ ) foi $25,7 \%$ inferior que o valor pago para machos ( R\$ 0,2170/kg).

No primeiro cenário de análise dos resultados econômicos, por gênero criado em cada núcleo, valores médios de custo operacional efetivo, de custo com mão de obra familiar, de custo com depreciação, de custo alternativo e de receitas totais foram expostos na Figura 3.

A análise econômica por gênero alojado nas unidades de produção demonstra que somente a criação de aves em modelo de integração foi capaz de conferir lucro econômico à atividade (núcleos de machos PR 01 e PR 02 e núcleos de aves não sexadas PR 03 e PR 04), pois o melhor resultado obtido em núcleos da empresa integradora (núcleo de machos IT 01) foi insuficiente para superar rendimentos que seriam gerados pela aplicação do capital em fundos bancários de renda fixa (Figura 3).

Os núcleos de machos PR 01 e PR 02 e os núcleos de aves não sexadas PR 03 e PR 04 foram os únicos que apresentaram lucro supernormal, enquanto a criação exclusiva de fêmeas, na melhor das hipóteses, gerou lucro financeiro às unidades que alojaram somente esse gênero de aves. Isso indica que, além da possibilidade de investimento do capital na caderneta de poupança, o alojamento exclusivo de machos ou de aves não sexadas (misto) também representaram alternativas econômicas mais vantajosas que o alojamento de fêmeas nas instalações de criação.

Diante da situação de resíduo positivo para alojamento exclusivo de fêmeas, as unidades de produção de aves desse gênero estariam propensas a interromper a atividade em favor de alternativas econômicas que apresentassem melhores perspectivas de retorno para o emprego de seus recursos (REIS, 2007) - tais como caderneta de poupança, alojamento exclusivo de machos ou alojamento de aves não sexadas.
Para tentar contornar essa situação, a empresa integradora realizava alojamento exclusivo de fêmeas somente em núcleos que comportassem alojamento simultâneo de machos em outra instalação pertencente ao mesmo proprietário. Mesmo assim, alguns produtores integrados preferiam optar pela outra alternativa econômica passível de aplicação da força de trabalho, do tempo e do capital disponíveis, que se tratava do alojamento restrito de aves não sexadas em todas as unidades de criação de seus núcleos.

Além da avaliação considerando a receita total obtida na atividade, a análise de resultados econômicos por gênero criado em cada núcleo foi realizada em cenário que as receitas secundárias não participaram da composição da receita total, como apresentado na Figura 4.

Constatou-se elevada dependência da atividade avícola de corte pela receita obtida com a venda de cama produzida nos aviários (Figura 4). As melhores situações observadas foram de resíduo nulo com cobertura parcial do custo com depreciação para os núcleos de machos PR 01 e PR 02, que poderiam permanecer na atividade, no máximo, até que a vida útil de seus bens expirasse. Nos demais casos, os núcleos de produção teriam de recorrer à captação de recursos externos para não abandonarem à atividade em curto prazo (REIS, 2007).

De maneira semelhante, Caldas et al. (2015) também indicaram a avicultura de corte não é promissora economicamente sem a venda de subprodutos gerados pela atividade. Os autores, ao realizarem análises econômicas no estado de São Paulo e Minas Gerais, demonstraram que unidades familiares de produção integrada operavam com prejuízo econômico sem a apropriação de receitas secundárias provenientes da venda de cama produzida nos aviários.

Segundo a Federação da Agricultura do Estado do Paraná - FAEP (2015), a diferença entre resultados economicamente promissores ou não, dependem de estratégias para reduzir custos e/ou aumentar as receitas. Alternativas para redução de custos envolvem decisões individuais, como o investimento na construção de mais galpões para diluir custos fixos, ou ações coletivas cooperativistas ou associativistas, que podem resultar em maior poder de barganha na negociação de insumos. Por outro lado, a elevação das receitas envolve alterações em aspectos de ordem técnica ou em questões atreladas à capacidade de negociação entre produtores rurais e empresas integradoras. 


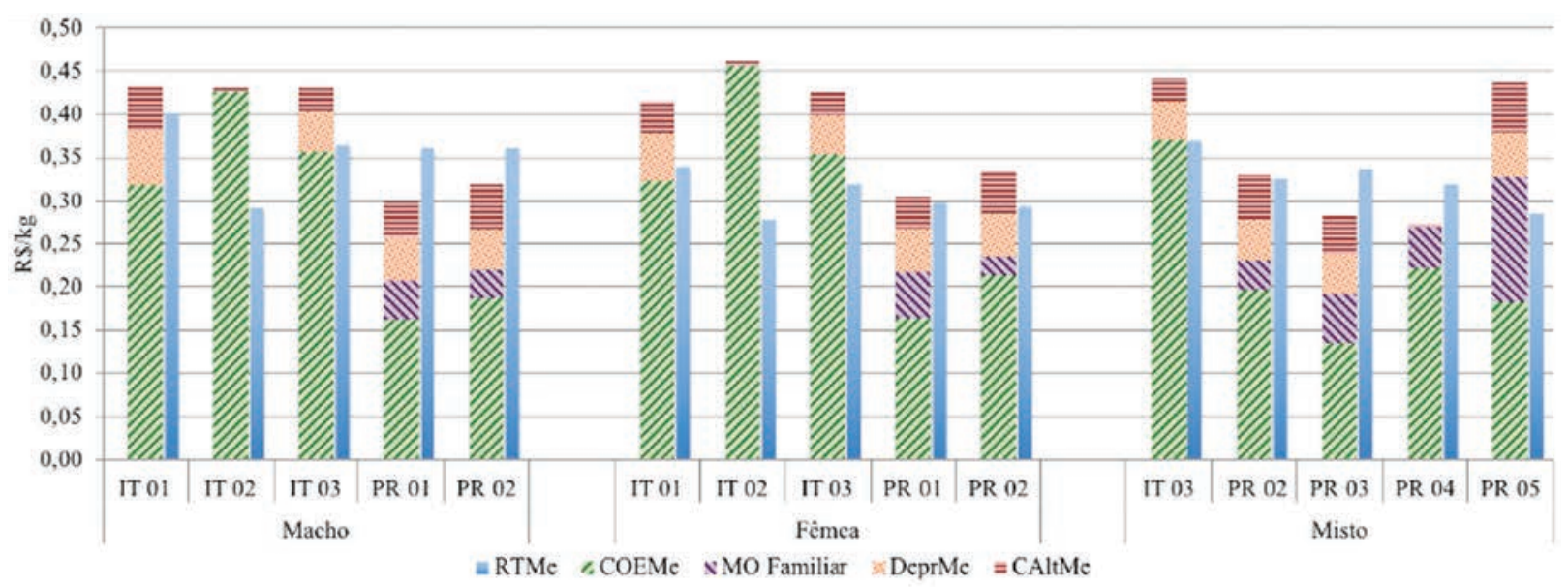

FIGURA 3 - Análise econômica por gênero alojado considerando a receita total média (RTMe), custo operacional efetivo médio (COEMe), custo médio com mão de obra familiar (MOFMe), depreciação (DeprMe) e custo alternativo médio (CAltMe) por ciclo de produção, em reais por quilograma de peso vivo produzido, para núcleos da empresa integradora (IT) e para núcleos de produtores rurais integrados (PR)

Fonte: Elaborado pelos autores, segundo resultados da pesquisa

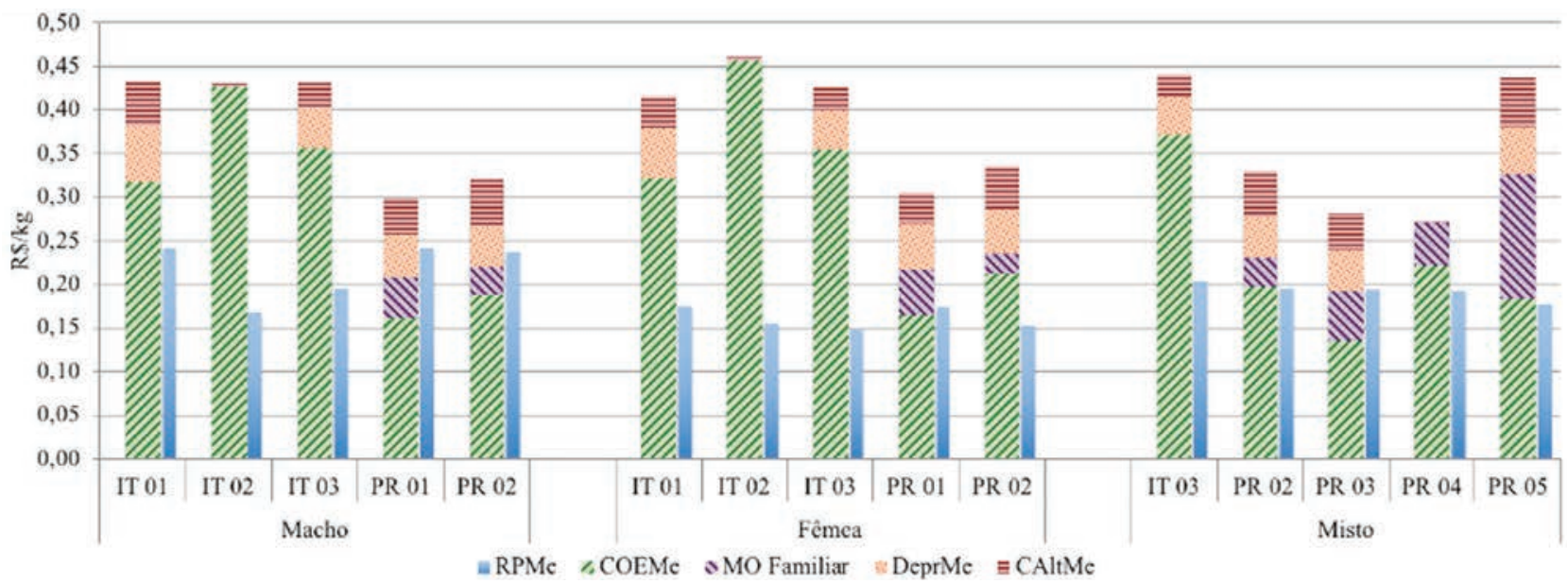

FIGURA 4 - Análise econômica por gênero alojado considerando a receita primária média (RPMe), custo operacional efetivo médio (COEMe), custo médio com mão de obra familiar (MOFMe) e com depreciação (DeprMe) e custo alternativo médio (CAltMe) por ciclo de produção, em reais por quilograma de peso vivo produzido, para núcleos da empresa integradora (IT) para núcleos de produtores rurais integrados (PR)

Fonte: Elaborado pelos autores, segundo resultados da pesquisa 


\section{CONCLUSÕES}

Esta pesquisa contribui com informações que podem auxiliar empresas integradoras em seus processos de tomada de decisões. Constatou-se que os melhores resultados econômicos e zootécnicos na produção de frangos de corte foram obtidos em unidades de produção exclusivas para machos sob estrutura de governança hibrida.

A avaliação dos indicadores zootécnicos indicou que os resultados obtidos em galpões restritos para machos foram melhores que o observado para criação de aves não sexadas e para lotes exclusivos de fêmeas, nesta ordem. Contudo, o potencial genético das aves poderia ter sido melhor aproveitado tanto nos núcleos de produtores rurais integrados como nos núcleos de criação da empresa integradora.

A produção de aves via hierarquia, independente do gênero das aves criadas, gerou piores resultados econômicos que os obtidos por meio da relação contratual com produtores rurais integrados. Verificou-se elevada dependência pela venda de cama produzida nos aviários, para todos os gêneros de aves alojadas, sem a qual nenhuma das unidades de produção se manteria em atividade em médio e longo prazos.

Para melhor elucidar o aproveitamento do potencial genético das aves, indica-se a necessidade de pesquisas futuras abrangendo empresas integradoras que utilizem tabelas de remuneração flexível e com pagamento de acordo com o sexo das aves alojadas nas unidades de produção rural.

\section{AGRADECIMENTO}

Os autores agradecem ao Conselho Nacional de Desenvolvimento Científico e Tecnológico (CNPq; No. 443089/2014-0) pelo financiamento do projeto.

\section{REFERÊNCIAS}

API, I. et al. Efeito da sexagem e linhagens sobre o desempenho e rendimento de carcaça de frangos de corte. Ciência Animal Brasileira, Goiânia, v. 18, p. 01-10, 2017.

ASSOCIAÇÃO BRASILEIRA DE PROTEÍNAANIMAL - ABPA. Indústria avícola: Nossa história. Disponível em: < http://www.brazilianchicken.com.br/pt/poultryindustry/background $>$. Acesso em: 16 abr. 2020.
CALDAS, E. O. L. et al. Análise econômica da produção de frangos de corte sob contratos de integração em pequenas unidades familiares. Organizações Rurais e Agroindustriais. Lavras: UFLA, v.17, n. 3, p. 351-368, 2015.

CALDAS, E.O.L.; LIMA, A.L.R.; LARA, L.J.C. Viabilidade econômica da produção de frangos de corte sob diferentes estruturas de governança. Arquivo Brasileiro de Medicina Veterinária e Zootecnia, Belo Horizonte, v. 71, n. 5, p. 1639-1648, 2019.

CARVALHO, F. de M.; FIÚZA, M. A.; LOPES, M. A. Determinação de custos como ação de competitividade: Estudo de um caso na avicultura de corte. Ciência e Agrotecnologia, v. 31, p. 812-827, 2007.

COMPANHIA NACIONAL DE ABASTECIMENTO CONAB. Custos de produção agrícola: A metodologia da Conab. Brasília, 2010. 60 p.

COBB-VANTRESS. Suplemento de crescimento e nutrição para frangos de corte: COBB 500. 2015. 14 p.

COASE, R.H. The Nature of the Firm. Economica, v. 4, n. 16 , p. 386-405, 1937.

DA COSTA, M. J. et al. Straight- run vs. sex separate rearing for 2 broiler genetic lines Part 1: Live production parameters, carcass yield, and feeding behavior. Poultry Science, v. 96, n. 08, p. 2641-2661, 2017.

FEDERAÇÃO DA AGRICULTURA DO ESTADO DO PARANÁ. Boletim Informativo. Curitiba, n. 1307, 2015. Disponível em: <https://issuu.com/sistemafaep/docs/ bi1307>. Acesso em: 02 dez. 2018.

FIGUEIRA, T. A. Fatores relevantes para o sucesso da avicultura de corte na agricultura familiar da Zona da Mata mineira: a percepção do produtor. 2009. $135 \mathrm{f}$. Dissertação (Mestrado em Administração) - Universidade Federal de Mato Grosso do Sul. Campo Grande, 2009.

FRANCO, C. et al. Análise dos contratos na avicultura de corte em Mato Grosso sob a ótica da nova econômica institucional (NEI). R. Econ. agroneg., v. 9, n. 2, p. 150-185, 2011.

GIROTTO, A. F.; SOUZA, M. V. N. Metodologia para o cálculo do custo de produção de frango de corte: Versão 1. Concórdia: Embrapa Suínos e Aves, 2006. 28 p. (Série Documentos, 109). 
GOTTARDI, C. P. F. F. et al. Efeito do sexo sobre desempenho produtivo e características de carcaça de frangos de corte. REVISTA DE AGRICULTURA NEOTROPICAL, v. 6, n. 2, p. 52-58, 2019.

GUIDUCCI, R. C. N. et al. Aspectos metodológicos da análise de viabilidade econômica de sistemas de produção. In: GUIDUCCI, R. C. N.; LIMA FILHO, J. R. de; MOTA, M. M. (Ed.) Viabilidade econômica de sistemas de produção agropecuários: metodologia e estudos de caso. Brasília, DF: Embrapa, 2012. p. 17-78.

HOFFMANN, R. et al. Administração da empresa agrícola. 7. ed. São Paulo: Pioneira, 1992. v. 1. 325p.

LAMPERT, J. A. Caderno didático de administração rural. In: Administração Rural. Santa Maria: DEAER/UFSM, 2003. 121p.

MARTINS, J. M. S. et al. Desempenho zootécnico de linhagens de frango de corte de crescimento rápido. PUBVET, v. 6, p. 1283-1288, 2012.

MATSUNAGA, M. et al. Metodologia do custo de produção utilizada pelo IEA. Agricultura em São Paulo, São Paulo, v. 23, n. 1, p. 123-139, 1976.

MEGLIORINI, E. Custos: Análise e Gestão. 3. ed. São Paulo: Pearson Universidades, 2012. 304p.

MENDES, A. A. Controles e registros e métodos de avaliação do desempenho de frangos de corte. In: MENDES, A. A. Curso de atualização em manejo de frangos de corte. Campinas: APINCO, 1989.

MENDES, A. A.; KOMIYAMA, C. M. Estratégias de manejo de frangos de corte visando qualidade de carcaça e carne. Revista Brasileira de Zootecnia, v. 40, p. 352-357, 2011. Disponível em: <http://hdl.handle. net/11449/141114>. Acesso em: 05 jun. 2019.

MIELE, M. et al. Metodologia para o Cálculo do Custo de Produção de Frango de Corte: Versão 2. Concórdia: Embrapa Suínos e Aves, 2010. 23 p. (Série Documentos, 140).
PEREIRA, C. M. M. A.; MELO, M. R.; SANTOS, M. H. O agronegócio do frango de corte: um estudo de caso sob a ótica da economia dos custos de transação. Informações Econômicas. Inst. Econ. agric., v. 37, n. 1, p. 07-17, 2007.

PINOTTI, R. N; PAULILLO, L. F. O. Rede de recursos dinâmicos de poder na agroindústria avícola em Santa Catarina e na macrorregião de Ribeirão Preto. In: XLV Congresso da Sober, 2007, Londrina. Anais... Londrina, 2007.

REIS, R. P. (Org.) Fundamentos de economia aplicada. Lavras: UFLA/FAEPE, 2007. v. 1. 95p.

RODRIGUES, W. et al. competitividade do sistema agroindustrial do frango de corte no Tocantins: o caso da empresa frango norte. REGE, v. 18, n. 2, p. 195-209, 2011.

SOUZA, M. de S., MICHELAN FILHO, T. Genética Avícola. In: MENDES, A. A.; NÄÄS, I. A.; MACARI, M. (Org.). Produção de frangos de corte. 1 ed. Campinas SP: Fundação APINCO de Ciência e tecnologia Avícola, 2004. v. 1, p. 23-36.

STRINGHINI, J. H. et al. Avaliação do desempenho e rendimento de carcaça de quatro linhagens de frangos de corte criadas em Goiás. Revista Brasileira de Zootecnia, v. 32, n. 1, p. 183-190, 2003.

UNIÃO BRASILEIRA DE AVICULTURA. A saga da avicultura brasileira: como o Brasil se tornou o maior exportador mundial de carne de frango. Rio de Janeiro: Insight; São Paulo: UBABEF, 2011. 120p.

UNITED STATES DEPARTMENT OF AGRICULTURE - USDA. Custom Query. Disponível em: < https://apps. fas.usda.gov/psdonline/app/index.html\#/app/advQuery>. Acesso em: 16 abr. 2020.

WILLIAMSON, O. E. The Economic Institutions of Capitalism. The Free Press. 1985. 449p.

YIN, R. K. Estudo de caso: planejamento e métodos. Tradução de Daniel Grassi. 3 ed. Porto Alegre: Bookman, 2005. 212 p. 